\title{
Conjunções adverbiais no português
}

\author{
Adverbial Conjunctions in Portuguese
}

\author{
Taísa Peres de Oliveira \\ Universidade Federal de Mato Grosso do Sul
}

\begin{abstract}
Resumo
Com base em pressupostos da Gramática Cognitiva (LANGACKER, 1987) e da Teoria da Gramaticalização (HOPPER; TRAUGOTT, 1993; LEHMANN, 1995), este trabalho tem como objeto de descrição a classe das conjunções adverbiais no português. $\mathrm{O}$ objetivo é rever o pensamento tradicional de que as conjunçôes adverbiais (i) são desprovidas de conteúdo lexical e (ii) pertencem a uma classe fechada. Ao contrário, discute-se que as conjunçôes adverbiais representam uma classe bastante diversificada no que diz respeito a sua tipologia estrutural e determinação categorial. São reconhecidos três polos de lexicalidade / gramaticalidade, dependendo do grau de concretude do significado manifestado pela conjunção. Os dados analisados foram coletados no $<$ www.corpusdoportugues.org $>$.
\end{abstract}

\section{Palavras-chave}

Conjunções adverbiais, lexicalidade, gramaticalidade, gradualidade.

\begin{abstract}
Based on Cognitive Grammar and on the Theory of Grammaticalization, this paper aims at describing the whole class of adverbial conjunctions in Portuguese. The aim of this study is to revise the traditional assumptions that adverbial conjunctions lack lexical meaning and that they are part of a closed class. Instead, it is suggested here that adverbial conjunctions are greatly diverse
\end{abstract}


with respect to both their structure and categorical status. Three groups of lexical/grammatical scales can be identified, depending on the degree of lexical meaning the conjunction displays. The data analyzed were collected at $<w w w . c o r p u s d o p o r t u g u e s . o r g>$.

\section{Keywords}

Adverbial conjunctions, lexicality, grammaticality, gradualness. 


\section{Introdução}

$\mathrm{E}$ ste artigo trata da natureza categorial das conjunçóes adverbiais sob um enfoque funcionalista. Trata, portanto, da gramática considerada conforme certo grau de arbitrariedade, determinado por fatores de natureza (i) cognitiva, (ii) funcional e (ii) contextual. Fica implicado aí o reconhecimento da fluidez entre as categorias e a aceitação da dinamicidade da gramática e da instabilidade do significado como características próprias do sistema linguístico.

O objetivo específico aqui é discutir o estatuto categorial das conjunções adverbiais no português, tradicionalmente classificadas como gramaticais. Tratase, em primeiro lugar, de rejeitar a visão tradicional de que o significado configure associaçōes estáveis a categorias fixas. A partir daí, considera-se a categorização de uma palavra como resultado de mapeamentos específicos entre diferentes categorias funcionais e lexicais de uma língua e coloca-se o uso linguístico como elemento motivador e regulador desse complexo. Todos os aspectos das categorias conceituais são entendidos como construcionais.

É assim que se coloca a noção de gradualidade e gradiência como essenciais à compreensão da natureza categorial dos elementos linguísticos. As categorias são concebidas, desse modo, como contínuas e seus membros são definidos em termos de prototipia e semelhança. Não há limites no distanciamento entre um membro prototípico e um membro mais periférico, desde que seja possível algum tipo de assimilação entre ambos.

Desse modo, a descrição realizada neste trabalho pretende demonstrar como as conjunções adverbiais podem variar no que diz respeito à sua gradualidade estrutural. Comumente concebidas como palavras gramaticais / funcionais, desprovidas de significado lexical, as conjunçôes adverbiais chamam atenção pelo fato de muitas vezes assumirem traços próprios de elementos lexicamente plenos. É o que atestam os vários trabalhos sobre gramaticalização de conjunçōes (PAIVA, 2001; OLIVEIRA, 2008; LONGHIN-THOMASI, 
2003). Evidencia-se, assim, a relevância da distinção lexical / gramatical para o entendimento das conjunções adverbiais no português.

A análise se constrói sobre as bases oferecidas pela Teoria da Gramaticalização (HOPPER; TRAUGOTT, 1993; BYBEE, 1994) em conexão com pressupostos cognitivistas (LAKOFF; JOHNSON, 1980; LANGACKER, 1987). O objetivo principal deste trabalho é descrever o comportamento das conjunçōes adverbiais no português. As especificações do objetivo são: (i) identificar propriedades definidoras da classe das conjunçôes adverbiais; (ii) buscar critérios que determinem o estatuto categorial das conjunções adverbiais no português.

Como resultado principal, este estudo propõe reconhecer três grupos de conjunçōes adverbiais no português. No primeiro grupo, as conjunçôes carregam um alto grau de conteúdo lexical. Esse parece ser o caso de conjunçôes como 'no caso (em) que' e 'à medida que', entre outros. Esse tipo de conjunção veicula significado lexical concreto, em que se verifica pouca mudança do significado original. Na verdade, conjunções desse grupo podem ser consideradas como usos mais gramaticais de uma fonte lexical e configuram construções elegíveis para gramaticalização. No segundo grupo, as conjunçōes ainda demonstram certo grau de significado lexical, só que, nesse caso, menos concreto que o anterior. No geral, o significado das conjunções passou por processos de mudança que levaram a uma abstratização mais acentuada do conteúdo lexical. Subjetivização e metáfora parecem ser os processos mais comuns às conjunçôes desse grupo, como se observa na formação de conjunções como 'supondo que' e 'desde que'. Conjunções desse grupo são menos produtivas e configuram casos incipientes de gramaticalização. No terceiro grupo, as conjunções são altamente abstratas e, por isso mesmo, apresentam-se com pouco material fônico e são aplicáveis a uma grande variedade de contextos, tais como as conjunçôes 'se', 'quando', 'porque' e 'embora'.

Este artigo está organizado do seguinte modo: na seção 1 apresentam-se os pressupostos teórico-metodológicos que norteiam este trabalho; na seção 2 discutem-se as principais propriedades das conjunçōes adverbiais no português; na seção 3 discute-se a natureza categorial das conjunções adverbiais e, por fim, na seção final apresentam-se algumas conclusões mais gerais.

\section{Questões teórico-metodológicas}

A análise das orações adverbiais realizada neste trabalho se baseia na crença de que as propriedades dos enunciados são adaptadas aos propósitos comunicativos 
dos interlocutores. A língua é usada como meio de comunicação humana em contextos culturais e psicológicos, fator que será determinante do modo como a língua é estruturada (BUTLER, 2003). Assim, ainda que o sistema linguístico demonstre certo grau de arbitrariedade, ele está tão intimamente ligado a fatores de natureza externa que não pode ser avaliado sem referência a esses (HALLIDAY, 1985; DIK, 1989; BUTLER, 2003; HENGEVELD; MACKENZIE, 2008).

Neste trabalho assume-se que as categorias linguísticas e as valorações semânticas são acomodadas na gramática conforme as funções cumpridas na atividade linguística. É por esta razão principal, que leva ao extremo a premissa funcionalista mais básica, que neste trabalho consideram-se dados de uso da língua.

\subsection{Material}

São objeto deste trabalho as conjunções do quadro 1, apresentadas conforme o tipo de relação semântica especificada, complexidade estrutural (simples ou complexa) e tipo de base lexical de origem (verbal, nominal, preposicional).

Os dados foram coletados no Córpus do Português <www.corpusdo portugues.org >. Um banco de dados com mais de 45 milhôes de palavras em quase 57.000 textos, que contemplam as variedades do português brasileiro e europeu, nos registros oral e escrito, num período que vai dos séculos XIV ao $\mathrm{XX}$. Os textos que compõem o corpus estão divididos entre os tipos acadêmico, notícias, ficção e oral.

Para este trabalho, especificamente, consideraram-se apenas dados dos séculos XIX e XX, contemplando os diferentes tipos de texto que compóem o corpus nas duas variedades: português brasileiro e português europeu. Evidentemente que não se negam aqui as diferenças dialetais entre as duas variedades. No entanto, tendo em vista que conjunçôes não devem, nos termos de Kortmann (1994), ser restritas a uma variedade/modalidade da língua, nenhum tipo de controle das variedades ou do gênero textual foi realizado.

\section{As conjunções adverbiais no português}

O objetivo desta seção é explicitar que unidade linguística se abriga sob o rótulo conjunção adverbial ${ }^{1}$ e, especificamente, demonstrar quais unidades linguísticas do português atendem aos critérios para serem incluídas nessa classe. 
$\mathrm{Na}$ maioria dos estudos sobre subordinação adverbial, o conceito de conjunção adverbial é dado como uma espécie de primitivo, um conceito teoricamente preestabelecido e, por isso mesmo, muito pouco discutido. Em geral, a definição tradicional da conjunção adverbial é sempre condicionada à sua função na oração adverbial como se vê, por exemplo, em Kortmann (1994, p. 4):

Subordinadores adverbiais são formas livres ou morfemas presos que especificam alguma relação intra-oracional semântica (ou: circunstancial, adverbial) entre a oração subordinada sobre a qual operam e a oração matriz modificada. ${ }^{2}$

Definições como essa implicam certa circularidade no estabelecimento do conceito de conjunção adverbial e, em última instância, também no de oração adverbial: se, por um lado, conceituam-se as conjunçōes adverbiais em termos de sua atuação sobre uma oração adverbial, por outro se conceitua a oração adverbial em termos de dependência gramatical, indicando a presença de conjunção como o componente gramatical definidor da dependência.

Essa definição acaba se tornando um problema para o entendimento da categoria conjunção adverbial. Primeiro, porque subordinação não necessariamente envolve oraçōes e, portanto, o conceito de conjunção adverbial não pode ser estabelecido com relação à sua função intraoracional apenas. Conforme demonstram Matthiessen e Thompson (1988), conjunções adverbiais podem atuar tanto entre sintagmas como também entre porções maiores do discurso, o que, de certo modo, invalida o critério. Em segundo lugar, as relaçōes entre oraçōes adverbiais podem ser estabelecidas sem presença de elemento subordinador, por meio da justaposição. Nesse caso, a conjunção adverbial deixa de ser uma condição necessária para o estabelecimento da relação intraoracional e, portanto, também não pode ser usada como critério definidor da relação adverbial.

Outro problema que se coloca à definição da conjunção adverbial diz respeito à multifuncionalidade desse item. É bastante comum encontrarmos conjunçōes adverbiais que servem a outras funçōes sem perder, ao menos em parte, sua função semântica de indicar uma relação de circunstância.

Além disso, existe ainda a questão da proximidade entre conjunçōes adverbiais e outros elementos como conjunçōes coordenadas, conjunçōes integrantes, pronomes relativos, pronomes interrogativos, advérbios e preposiçōes. Kortmann (1994) afirma que as conjunções adverbiais estabelecem conexôes com diversas categorias e, assim, 
participam de continua em vários domínios, o que, de certo modo, dificulta o estabelecimento de critérios mais rígidos para sua definição.

No domínio das relações entre orações, as conjunçôes adverbiais ocupam uma posição intermediária entre conjunções coordenativas e conjunções integrantes. Primeiro porque a fronteira entre os diferentes tipos de oração ébastante diluída, como demonstram os trabalhos de Lehmann (1988), Hopper e Traugott (1993), Neves (2000, 2012) e Hirata (2005). Além disso, a própria funcionalidade do item como indicador de circunstância também pode ser entendida num continuum, já que outros elementos, como conjunçōes coordenadas, também podem construir a relação circunstancial entre orações, ainda que essa não seja sua função principal, como ilustram os exemplos:

(1) O cara pode ser "animal" e ter notas ruins (http://www.corpusdoportugues. org/x4.asp?t=26400\&ID=2624503419Or:Br:Intrv:Cid) - Concessão

(2) Então, no final do ano, as contas são zeradas e, aquilo que sobrou é devolvido aos cofres públicos, (19Or:Br:Intrv:Cid) - Tempo

Outra conexão pode ser percebida entre a conjunção adverbial e outras categorias sintáticas, tal como se nota entre substantivo, sintagma nominal e conjunção adverbial. Por exemplo, Thompson e Longacre (1985) demonstraram que orações de tempo, modo e lugar podem começar como orações relativas, posteriormente reduzidas a sintagmas nominais relativos, tais como as locuçóes "na hora em que" e "de modo que". Existe ainda a proximidade entre conjunções adverbiais, advérbios e preposições. Muito frequentemente, advérbios e preposições desenvolvem-se em conjunções adverbiais, como se vê, para o português, nas locuçôes "logo que", "ainda que" e "desde que".

Fica revelado, portanto, que a definição tradicional de conjunção adverbial esbarra numa série de questões nem sempre consideradas. Para uma definição mais eficiente, é necessário um conjunto de critérios que conjuguem, ao mesmo tempo, forma, função e todas as conexões que a conjunção adverbial faz com outros domínios. É nesta direção que Kortmann (1994) elenca os seguintes critérios definidores das conjunçôes adverbiais: (i) São formas não flexionáveis. Não estão sujeitas à marcação de caso, número e gênero, o que as distingue de pronomes relativos; (ii) Atuam sobre uma oração que funciona como um adjunto (geralmente finita); (iii) Não assumem funçōes argumentais de sujeito/objeto na oração em que participam; (iv) Assumem uma posição fixa na margem da oração; (v) Não pertencem a um determinado registro ou modalidade da língua. 
Ressalte-se, no entanto, que os critérios de Kortmann (1994) identificam as propriedades morfossintáticas e semânticas do núcleo prototípico de uma categoria relativamente heterogênea. Ao assumir o caráter não discreto das categorias e o papel do componente contextual na determinação semântica, fica implicado também o reconhecimento de que alguns elementos poderão estar mais próximos do centro ao passo que outros, mais distantes, manifestarão em menor grau as propriedades definidoras da categoria.

Com base nessas distinções, pode-se identificar uma enorme variedade de unidades linguísticas no português que atuam como conjunções adverbiais. Além das já tradicionais conjunçōes se, quando, como, que, enquanto, para, porque, pois, embora, porquanto, conquanto que, é possível incluir aí uma série de elementos e construções que claramente cumprem as mesmas funções e demonstram, ao menos em parte, as mesmas propriedades sintático-semânticas. Assim, este trabalho considera, ainda, como conjunções adverbiais: conforme, consoante, segundo, dado que, visto que, posto que, a não ser que, supondo que, desde que, antes que, depois que, logo que, assim que, sempre que, já que, uma vez que, no momento (em) que, contanto que, a menos que, mesmo que, ainda que, apesar (de) que, por causa (de) que, no caso (em) (que), a fim de que, de modo que, de maneira que, à medida que, sem que, para que.

A identificação das conjunções adverbiais do português partiu do funcionamento desses elementos como introdutores de um elo semântico entre uma oração secundária e uma oração matriz. As relações semânticas foram classificadas conforme apresentadas em Neves (2000). Tomem-se as seguintes ocorrências:

(3) Supondo que a fiscalização, e depois a classificação das doenças seja um facto adquirido [oração secundária], resta ainda outro obstáculo a ultrapassar, referido por Rui Couceiro: "não há dados de morbilidade de doenças». [oração matriz] (19N:Pt:Leira)

(4) E por isso quero continuar debatendo mudanças com meus colegas da comissão especial [oração matriz] - desde que sejam para atender ao consumidor [oração secundária]. (19Or:Br:Intrv:ISP)

(5) A medida que o progresso aumenta [oração secundária], aprimoramos a sofisticação e ampliamos o sentimento de vazio [oração matriz]. (19:Fic:Br:Costa:Sala) 
(6) Ocorre que a primeira tentativa de debate, realizada anteontem por a Associação Comercial de o Rio de Janeiro, não merece essa qualificação [oração matriz], dado que o seu regulamento não permitia perguntas diretas de um candidato para outro [oração secundária]. (19N:Br:Folha)

(7) Todavia, verifiquei que não me levava a parte nenhuma [oração matriz], $\underline{a}$ não ser que fosse para algum convento [oração secundária]. (19Or:Pt:Intrv:Web)

(8) Sempre que houve denúncias de excessos [oração secundária], apuramos os fatos e punimos os responsáveis [oração matriz]. (19N:Br:PA)

(9) Logo que o senhor assumiu o Detran [oração secundária], fechou as portas do órgão para apurar fraudes [oração matriz]. (19Or:Br:Intrv:Com)

(10) Assim que cheguei ao Rio [oração secundária], comecei a vida trabalhando como propagandista de laboratórios farmacêuticos [oração matriz]. (19Or:Br:Intrv:ISP)

(11) Depois que eu sai do Fortaleza [oração secundária] ainda joguei seis meses no Tiradentes [oração matriz]. (19Or:Br:Intrv:Pov)

(12) O objectivo militar nunca chegou a ser alcançado [oração matriz], $\underline{u m a}$ vez que nunca foram encontradas armas de destruição maciça em território iraquiano [oração secundária]. (19Ac:Pt:Enc)

(13) Aquelas regras de comportamento não precisam de ser justificadas pela transcendência [oração matriz], a menos que ela lhes venha dar uma carga mágica que facilite a sua aplicação [oração secundária]. (19:Fic:Pt:Alçada:Lacos)

Vê-se, claramente, que as orações indicadas como oração secundária atuam como adjuntos da oração matriz. Essas orações servem para construir uma situação suplementar que modifica a situação principal. A partir daí, acrescentam especificações semânticas adicionais que realçam, restringem ou condicionam o conteúdo descrito na oração matriz, tal como um adjunto. Realizam, portanto, casos de subordinação adverbial.

Mais relevante, ainda, parecem ser as propriedades morfossintáticas manifestadas por essas construções, que as aproxima muito das conjunções adverbiais prototípicas. Como resultado da abstratização (ainda que parcial) do significado de suas fontes, as conjunções acabam sofrendo algumas restrições formais e perdem características próprias de seus usos originais como itens lexicais plenos. 
Um primeiro dado que revela essa restrição é a posição à margem da oração assumida por esses elementos: em português, conjunções ocorrem necessariamente em posição inicial, posição em geral reservada para elementos com alguma relevância. Ao observar as ocorrências em (14) e (15), nota-se que nesses contextos os itens 'dar' e 'caso' não podem ter sua posição alterada sem que isso acarrete a agramaticalidade da oração:

(14) Dado que utiliza a linha telefónica, o viewdata é um sistema de informação interactivo de duas vias. (19Ac:Pt:Enc)

*utiliza, dado que, a linha telefónica, o viewdata é um sistema de informação interactivo de duas vias.

(15) Suape pode ser o diferencial de Pernambuco diante dos outros estados do Nordeste, caso seja um porto com excelente infra-estrutura (19Or:Br:Intrv:Com)

* Suape pode ser o diferencial de Pernambuco diante dos outros estados do Nordeste, seja caso um porto com excelente infra-estrutura (19Or:Br:Intrv:Com)

Diferentemente dos usos originais, quando empregados como conjunção adverbial, a variabilidade de posição ora experimentada pelos lexemas é restringida pela função que cumprem como conjunção adverbial: a de introduzir uma oração dependente.

Outro aspecto que evidencia o uso desses elementos como conjunções adverbiais diz respeito à invariância flexional neles verificada. A esse respeito examinem-se, em primeiro lugar, as conjunçōes formadas a partir de verbos. Vêse nelas que a base da conjunção não pode variar quanto à flexão de tempo, modo, número ou pessoa, como demonstram as ocorrências:

(16) Dado que os alicerces podiam suportar mais carga, o edifício foi muito aumentado em altura (19Ac:Pt:Enc)

* Dando que os alicerces podiam suportar mais carga, o edifício foi muito aumentado em altura

* Deu que os alicerces podiam suportar mais carga, o edifício foi muito aumentado em altura 
(17) então eu iria pra casa - ia dar uma - vistoria na geladeira pra ver o que que tinha lá - e supondo que tivesse - carne né? faria - bife - com batatas porque sei que com certeza vocês iriam adorar batatas fritas (19Or:Br:LF:SP)

* supôs que tivesse - carne né? faria - bife

Como nessas ocorrências os elementos estão sendo usados como conjunçōes adverbiais, e não como verbos, eles perdem (temporariamente) a propriedade da flexão. Outro fato que colabora para essa restrição é que as marcas flexionais carregadas pela base verbal, muitas vezes, servem ao próprio sentido adverbial que essa conjunção constrói. Por exemplo, na formação da conjunção 'dado que', o significado lexical do verbo 'dar' soma-se às noçôes temporais especificadas pelo particípio; a partir daí uma informação é introduzida como pressuposta e serve como moldura para uma enunciação subsequente.

Também é interessante a restrição quanto à forma observada nas conjunções formadas a partir de substantivos, que não podem ser flexionadas quanto a número e gênero, como se vê nas formações a seguir:

(18) À medida que realizamos alguma atividade há uma demanda maior de sangue oxigenado. (19Ac:Br:Enc)

* Às medidas que realizamos alguma atividade há uma demanda maior de sangue oxigenado.

(19) Caso fique bom, tenha algum tipo de sucesso, quero fazer outros. (19Or:Br:Intrv:ISP)

${ }^{*}$ Casos fique bom, tenha algum tipo de sucesso, quero fazer outros.

Outro fator pertinente para a consideração das construções em exame como conjunções adverbiais é o fato de elas não participarem da estrutura argumental da oração. Quando usadas como conjunçôes, esses elementos não assumem posições na construção da predicação central - aplicação de termos a um predicado nuclear. Consequentemente, também não podem codificar morfossintaticamente as funções de sujeito e objeto.

Fica facilmente comprovada a reflexão principal que se faz neste trabalho: a de que a classe das conjunções adverbiais é bem maior e mais variada do que se pensava. Levando em conta a instabilidade própria da gramática e, em última instância, a das categorias, muitas construções gramaticais podem fazer parte do 
que se rotulam conjunções adverbiais em português. Entende-se que essa seja uma consequência natural do uso linguístico: o encaminhamento de novas funções para serem acomodadas pelo sistema da língua. A formação de conjunções adverbiais liga-se, especialmente, à tendência de gramaticalização, ou seja, a passagem dos itens lexicais para funções (mais) gramaticais.

As conjunções adverbiais podem ser classificadas com relação à sua complexidade interna. Por esse critério, distinguem-se conjunçôes simples, formadas de apenas um elemento formal, e as complexas, formadas por mais de um elemento. Nesse caso, considera-se, ainda, a natureza de sua base derivadora. Esses critérios são relevantes uma vez que possibilitam observar padrões nos processos de gramaticalização, de um lado, e, de outro, a correlação entre os tipos de estruturas e os diversos domínios conceituais envolvidos na formação das conjunçōes adverbiais.

As conjunções adverbiais são classificadas, ainda, quanto ao tipo de relação circunstancial que codificam. Relações de circunstância são estabelecidas entre uma oração matriz e uma oração dependente, tradicionalmente denominada oração adverbial. No geral, os autores evocam termos como modificação semântica para dar conta da função desempenhada pelas orações adverbiais.

Halliday (1985) concebe as orações adverbiais como um tipo de hipotaxe de realce, oração que serve para modificar a situação descrita na oração principal, acrescentando algum tipo de informação suplementar. Visão semelhante é apresentada por Matthiessen e Thompson (1988), que entendem as orações adverbiais como um tipo de satélite que participa das relaçōes retóricas núcleosatélite do discurso com a função de auxiliar os objetivos centrais. Em Hengeveld e Mackenzie (2008), as oraçôes adverbiais são concebidas como uma espécie de modificador oracional, uma oração dependente que atua como adjunto de uma oração matriz.

Vê-se, portanto, que as oraçôes adverbiais são sempre concebidas em termos da modificação semântica que promovem sobre a oração matriz e serão classificadas de acordo com a natureza da modificação exercida. A partir daí classificam-se, também, as conjunções adverbiais nos termos da função semântica que cumprem nas orações, como se vê no quadro 1 a seguir. 
QUADRO 1

Tipos de Conjunções Adverbiais no Português

\begin{tabular}{|c|c|c|c|c|c|}
\hline & \multicolumn{5}{|c|}{ CONJUNÇÕES ADVERBIAIS } \\
\hline & \multirow[t]{2}{*}{ Simples } & \multicolumn{4}{|c|}{ Complexas } \\
\hline & & Base verbal & Base adverbial & Base nominal & $\begin{array}{c}\text { Base } \\
\text { preposicional }\end{array}$ \\
\hline Temporal & $\begin{array}{l}\text { quando; } \\
\text { enquanto }\end{array}$ & & $\begin{array}{l}\text { antes que; depois que; } \\
\text { logo que; assim que; } \\
\text { sempre que }\end{array}$ & & desde que \\
\hline$\overline{\text { Causal }}$ & \begin{tabular}{|l|} 
porque; como; \\
pois; porquanto \\
posto que
\end{tabular} & $\begin{array}{l}\text { dado que; } \\
\text { visto que, }\end{array}$ & já que; uma vez que & por causa (de) que & desde que \\
\hline Condicional & se; caso & $\begin{array}{l}\text { a não ser que; } \\
\text { supondo que }\end{array}$ & $\begin{array}{l}\text { contanto que; } \\
\text { uma vez que; } \\
\text { a menos que }\end{array}$ & no caso (de) (que); & $\begin{array}{l}\text { desde que; } \\
\text { sem que }\end{array}$ \\
\hline Concessiva & $\begin{array}{l}\text { embora; } \\
\text { conquanto }\end{array}$ & posto que & $\begin{array}{l}\text { mesmo que; } \\
\text { ainda que; } \\
\text { apesar (de) que }\end{array}$ & & \\
\hline Final & para & & & $\begin{array}{l}\text { a fim de que; } \\
\text { de modo que; } \\
\text { de maneira que }\end{array}$ & para que \\
\hline Consecutiva & que & & & $\begin{array}{l}\text { de modo que; } \\
\text { de maneira que; }\end{array}$ & \\
\hline Modal & & & como & & sem (que) \\
\hline Conformativa & & & $\begin{array}{l}\text { conforme; consoante; } \\
\text { segundo; como }\end{array}$ & & \\
\hline Proporcional & & & & à medida que & \\
\hline
\end{tabular}

\section{A natureza categorial das conjunções adverbiais em português}

Esta análise constrói-se sob o entendimento de que uma categorização não pode simplificar-se na noção de que as categorias têm limites rígidos e bem delimitados. Considerada a natureza dinâmica e construcional da gramática, são especialmente relevantes o papel do contexto na determinação do significado e a gradualidade estrutural e a multifuncionalidade próprias dos elementos linguísticos.

Discutir a natureza categorial dos itens implica, em primeiro lugar, aceitar que a classificação linguística não pode ser definida em termos de propriedades necessárias e suficientes. É preciso invocar a noção de prototipia, a partir da qual 
entende-se que alguns elementos podem ser mais representativos de uma categoria que outros, reconhecendo-se a existência de categorias intermediárias e outras periféricas (CROFT, 1991; TAYLOR, 2004). Nesta direção, alguns membros compartilham as mesmas propriedades semânticas, de certa forma mais diluídas em membros mais distantes do núcleo prototípico.

Mais relevante para a definição da categoria é que seus membros compartilhem as mesmas funções e contribuam de modo semelhante na constituição dos enunciados (AARTS, 2006). Em outras palavras, em última instância o que se espera de membros de uma mesma classe é que tenham as mesmas funções proposicionais, e não necessariamente as mesmas propriedades estruturais.

Ao contrário dos objetos físicos / concretos, elementos linguísticos são resutlados de processos conceituais e convencionais, o que impossibilita ainda mais as definições ontológicas. $\mathrm{O}$ sistema linguístico não está organizado por conceitos individuais, mas por diferentes domínios conceituais que formam uma rede complexa. Como apresentam pontos de intersecção, as categorias não podem ser claramente distinguidas e devem ser tratadas em termos de contiguidade.

Chega-se, então, à consideração da gradualidade como traço inerente às categorias (AARTS, 2004). Como resultados de processos universais e instáveis, as categorias não podem mesmo ser consideradas como entidades discretas, como se percebe, claramente, na própria evolução da gramática. A mudança linguística se dá de forma gradual, como um processo dinâmico em que formas passam a codificar relações que ou não eram codificadas antes ou que eram codificadas diferentemente.

As conclusões a que se chega é que a noção de gradualidade é relevante, então, em dois domínios da organização gramatical: primeiro, no estabelecimento das fronteiras entre as categorias - possibilitando zonas de intersecção - e, segundo, no próprio modo como as categorias são organizadas internamente, possibilitando a coexistência de membros com diferentes graus de determinação categorial.

É com base em tais assunções que se analisa a categoria conjunção adverbial como uma classe difusa que abriga, ao mesmo tempo, elementos mais básicos, de natureza altamente abstrata, e elementos que carregam certo grau de significado lexical. Partindo da realidade dos usos, a verificação que se fez revela que as conjunções adverbiais no português se organizam em torno de três polos de lexicalidade ( gramaticalidade: 1) o das conjunçóes lexicais; 2) o das conjunçóes lexicais com mudança acentuada de significado; e 3) o das conjunçóes gramaticais. 
No primeiro tipo, as conjunções adverbiais se caracterizam pelos traços lexicais que manifestam e pela concretude do seu significado. Nessas conjunçôes, o significado da fonte de origem encontra-se ainda bastante preservado. De fato, traços desse significado é que especificam a relação de circunstância estabelecida entre a oração dependente e a matriz. Tome-se a seguinte conjunção:

(20) No caso em que as disposiçóes vigentes autorizem o uso de um prospecto preliminar ou a realização de publicidade prévia à autorização, o material deve explicar seu caráter preliminar. (19Ac:Br:Enc)

Nessa ocorrência, o próprio núcleo da conjunção exprime o sentido de conjuntura / contingência determinante para a indicação da situação hipotética / mundo possível característico da conjunção condicional. O que ocorre, nesse caso, é uma extensão desse significado, que deixa de indicar uma conjuntura específica / determinada e passa a indicar uma conjuntura aberta, não referencial. Em outras palavras, a expressão não mais introduz um referente específico no discurso, mas constrói uma situação abstrata. É a partir daí que o sentido condicional é construído. Veja-se outro caso:

(21) No momento que ele chegou em C, ele vai manter a trajetória em linha reta. (19Ac:Br:Lac:Thes)

Aí a especificação de temporalidade é expressa pelo próprio núcleo nominal da conjunção, cujo significado original é o de indicar um espaço transcorrido de tempo / circunstância. O que a conjunção faz é estender esse significado que deixa de indicar, em si própria, uma circunstância determinada para relacionar o período descrito no evento 'ele chegou' como o período que antecede o evento principal.

Isso também ocorre com outras conjunções desse núcleo, nas quais se verifica uma extensão do significado original de seus núcleos para indicar uma oração circunstancial. No continuum lexicalidade / gramaticalidade, essas conjunçôes estariam mais próximas ao polo lexicalidade. Na verdade, esses conectivos podem ser considerados como usos mais gramaticais de uma fonte lexical, especialmente verbos e substantivos, e podem ser tratados como casos de construçóes. Estão mais próximas desse núcleo conjunçôes como: no caso em que, no momento em que, a fim de que; de modo que; de maneira que, antes que, depois que, logo que, sempre que, à medida que, conforme, consoante, segundo, por causa (de) que. As construções desse grupo são elegíveis para gramaticalização. 
No segundo núcleo, as conjunções demonstram um grau de lexicalidade bem menor. Isso porque o significado dessas conjunções passou por mudanças que levaram a uma abstratização maior do conteúdo lexical. Os processos mais comuns que se notam aí são subjetivização e metáfora. Pela subjetivização, certas expressões desenvolvem valores epistêmicos, marcas gramaticais da subjetividade do falante. É o que se nota no seguinte exemplo:

(22) Supondo que a direção de lançamento do corpo forme com o solo um ângulo temos que a componente horizontal da velocidade é igual a (19Ac:Br:Enc)

Veja-se aí que a conjunção funciona como uma espécie de operador de modalidade hipotética. A conjunção indica que a proposição por ela introduzida deve ser lida como uma hipótese, como um conteúdo aberto. A partir daí constrói-se o significado condicional. Esse sentido é derivado dos traços lexicais do verbo base da conjunção, que exprime originalmente o sentido de hipotetizar, conjeturar.

A metáfora, talvez o processo mais comum para formação de conjunções adverbiais, ocorre quando se tem a inferência de um domínio fonte para outro domínio, menos concreto. É o que se observa na formação da conjunção 'desde que'. O item lexical 'desde' originalmente circunscreve um ponto de origem no espaço. ${ }^{3}$ Esse sentido é mapeado para um domínio mais abstrato, indicando ponto de origem no tempo. A partir daí tem-se a conjunção temporal 'desde que', que especifica a origem temporal para a ocorrência do evento descrito na oração matriz. Esse significado pode, ainda, ser mapeado para um domínio mais abstrato, em que marca um ponto de origem no discurso, dando origem ao sentido condicional. É o que mostram as ocorrências:

(23) Desde que assumi o governo pensei que seria necessário realizar reformas estruturais na economia italiana. (19Or:Br:Intrv:ISP) TEMPO

(24) Essas conseqüências são previstas desde que eles façam evidentemente um um um exame pré - nupcial ou pré-natal (19Or:Br:LF:Recf) CONDIÇÃO

Em (23), a conjunção 'desde que' funciona como conjunção temporal ao indicar o ponto inicial no tempo - assumi o governo - a partir do qual um evento principal se realiza; instaura-se aí o sentido temporal. Por outro lado, em (24), 
a conjunção indica um ponto inicial no discurso - eles façam evidentemente um exame pré-nupcial ou pré-natal - a partir do qual um argumento descrito na proposição principal se valida; tem-se aí o sentido condicional.

Verifica-se nesses casos um significado mais abstrato, resultante de uma inferência do significado lexical do núcleo formador da conjunção. Devido às mudanças por que passaram, essas conjunções são bem mais fundidas que as discutidas anteriormente. Fazem parte desse núcleo as conjunçôes: caso, uma vez que, desde que, dado que, posto que, visto que, ainda que, mesmo que, já que.

No continuum lexicalidade / gramaticalidade esse núcleo estaria situado ao meio do caminho, já que ainda apresenta traços lexicais, porém relativamente menos concretos. Esse núcleo é menos produtivo que o primeiro e as conjunções aí podem ser consideradas casos iniciais de gramaticalização.

Os dois tipos se diferenciam pelo fato de que, no primeiro, traços originais do significado atuam diretamente no estabelecimento da relação circunstancial. Já no segundo grupo, é fundamental que tenha havido algum tipo de mudança. Isso porque é justamente a mudança do significado original que concorre para que a relação circunstancial seja estabelecida.

Por fim, no terceiro núcleo identificado, as conjunções são altamente abstratas e parecem desprovidas de conteúdo lexical. A maioria delas se formou no desenvolvimento do latim para o português ou ainda nos períodos mais iniciais da língua (BARRETO, 1999). O conteúdo semântico dessas conjunções é bastante desgastado e, portanto, altamente abstrato.

Como consequência, essas conjunções apresentam-se com pouco material fônico e são aplicáveis a uma grande variedade de contextos. Ressalte-se, também, que embora formem um grupo minoritário, devido ao estatuto mais gramaticalizado e abstrato, a verificação nos dados mostra que essas conjunções são altamente produtivas, especialmente na linguagem oral, como já era esperado. Essas conjunções estão mais próximas do polo gramaticalidade. Fazem parte desse núcleo as conjunçôes adverbiais se, quando, porque, pois, como, enquanto, para e embora.

(25) Embora seja um país pobre, o povo é extremamente afetivo. (19Or:Br:Intrv:ISP) 
(26) Quando eu era mais nova, fazia planos. Hoje não. (19Or:Br:Intrv:Cid) Fica evidente que a classe das conjunçôes é bem menos fechada e estanque do que se pensava. Ao contrário, conjuga elementos com diferentes graus de lexicalidade / gramaticalidade, evidenciando o caráter transitório e evolutivo da gramática. Chegase, assim, ao entendimento de que a categoria pode ser mais bem representada se concebida em termos de continualidade, e não simplesmente pela dicotomia lexical / gramatical. A classe das conjunçôes adverbiais em português pode ser representada pela escala abaixo, adaptada de Hopper e Traugott (1993) e de Keizer (2007):

\section{QUADRO 2}

Cline de lexicalidade / Gramaticalidade das conjunções

\begin{tabular}{l|l|l|l|l}
\hline \multicolumn{1}{|c}{$>$} & \multicolumn{3}{c}{ palavra gramatical $>$ clítico $>$ afixo } \\
\hline primário & secundário & primária & secundária & \\
\hline no caso (em) que, & caso, uma vez & se, & & \\
no momento (em) & que, desde que, & quando, & & \\
que, a fim de que; & dado que, posto & porque, & & \\
de modo que; & que, visto que, & pois, & & \\
de maneira que, & contanto que, & como, & & \\
antes que, depois & a não ser que, & enquanto & & \\
que, logo que, & ainda que, & embora, & & \\
sempre que, & mesmo que, & para, que & & \\
por causa (de) que, & já que & & & \\
à medida que, & & & \\
apesar (de) que, & & & \\
conforme, consoante, & & & \\
segundo & & & \\
\hline
\end{tabular}

A escala prevê um contínuo de lexicalidade / gramaticalidade, no qual a extrema esquerda representa o grau máximo de lexicalidade - com os itens de conteúdo - e a extrema direita o grau máximo de gramaticalidade - em que estão os afixos. Pensando formalizar essa gradualidade, Keizer (2007) separa itens primários (mais representativos) e secundários (menos representativos) em cada um dos núcleos. Conjunçôes seriam, no polo lexicalidade, itens secundários, já que possuem um grau menor de significado concreto, e itens secundários no polo gramaticalidade, já que, apesar de manifestarem um sentido gramatical, constituem formas livres. 


\section{Considerações finais}

Como parte essencial de qualquer atividade humana, a noção de categorização coloca-se como fundamental ao tratamento da linguagem: qualquer proposta de teorização linguística reconhece, de um modo ou outro, a existência de certas categorias. Não à toa Labov (2004) afirma que a linguística é o próprio estudo das categorias. No entanto, apesar da centralidade do conceito, a uniformidade e a pouca consistência no modo como o termo categoria é empregado na linguística acaba se tornando um grande complicador.

A reflexão que se faz neste trabalho sobre o conceito da categoria conjunção adverbial se dá em duas frentes. Primeiro, consideram-se critérios internos e de natureza estritamente estrutural, que envolvem principalmente a noção de protótipos. Por esse caminho, revela-se que a classe das conjunções adverbiais, a espelho do próprio sistema linguístico, é bastante instável e heterogênea. A conclusão principal aí é que não se trata de uma classe fechada. Ainda, os elementos que se abrigam sob o rótulo conjunção adverbial têm uma natureza estrutural bastante diferenciada: elementos e construções de natureza gramatical diversa podem entrar nessa classe.

Levando-se em conta critérios externos, verifica-se o papel motivador das determinações semânticas e pragmáticas, e considera-se, principalmente, a noção de gradualidade. Por esse caminho, verfica-se a natureza gradual da categoria conjunção adverbial para o português. Chega-se a duas conclusões principais. Primeiro, a visão das conjunções adverbiais como classe gramatical não corresponde à realidade dos fatos verificada nos dados. Conjunçōes adverbiais podem, sim, veicular significado lexical. Em segundo lugar, a distinção lexical / gramatical idealizada por alguns autores, assim dicotômica, também não reflete a realidade do funcionamento e sistematização dessa categoria. Aqui, propõe-se reconhecer três núcleos de conjunções adverbiais, quanto ao estatuto categorial: 1) um mais próximo ao polo lexicalidade, no qual os exemplos veiculam alto grau de conteúdo lexical; 2) um mais ao meio do continuum de lexicalidade / gramaticalidade, no qual os exemplos apresentam-se com significado lexical bem menos concreto; e por fim 3) um mais próximo ao polo gramaticalidade, no qual os exemplos têm um significado básico e altamente abstrato.

Ora, sabe-se que nenhuma pesquisa pode dar-se por finita. Os resultados encontrados apontam novos caminhos a serem traçados. Embora já se tenha discutido exaustivamente os processos de mudança linguística envolvidos na 
formação de conjunções, pouco se fala sobre os domínios fonte a partir dos quais novas conjunções se formam. No geral, a discussão focaliza apenas os tipos de estruturas que podem dar origem a sentidos adverbiais.

Um tratamento que falta é aquele que verifica a recorrência de determinados domínios conceituais e dos tipos estruturais que concorrem para a formação de conjunções, com base em uma verificação tipológica. Ainda que conjunçôes adverbiais possam se desenvolver a partir de diferentes significados, acredita-se que a base desses significados, uma vez que advinda de determinações de natureza cognitiva, seja bem restrita. Assim, um estudo tipológico fornecerá as bases para o entendimento dos padrões construcionais e conceituais relevantes para a formação de conjunções adverbiais.

\section{Notas}

${ }^{1}$ Cabe esclarecer que neste trabalho não se faz nenhuma diferença terminológica quanto ao uso dos termos conjunção, conector ou conectivo.

${ }^{2}$ Adverbial subordinators are free forms or bound morphemes which specify some semantic interclausal (or: circumstantial, adverbial) relation between the subordinate clause over which they operate and the modified matrix clause.

${ }^{3}$ Para a consideração da preposição 'desde' como elemento lexical, cf. Pezatti et al (2010).

\section{Referências}

AARTS, B. Conceptions of gradience in the history of linguistics. Language Sciences, v. 26, p. 343-389, 2004.

AARTS, B. Conceptions of categorization in the history of linguistics. Language Sciences, v. 28, p. 361-385, 2006.

BARRETO, T. M. M. Gramaticalização das conjunçōes na história do português. Salvador, 1999, 326 f., v. I e II. Tese (Doutorado em Letras e Lingüística) - Instituto de Letras - Universidade Federal da Bahia.

BUTLER, Christopher. Structure and Function: Guide to Three Major StructuralFunctionalist Theories. Part I Approaches to Simple Clause. Amsterdam/Philadelphia: John Benjamins, 2003. 
BYBEE, J. et al. The evolution of grammar: Tense, aspect and modality in the languages of the world. Chicago: The University of Chicago Press, 1994.

CROFT, W. Syntactic Categories and Grammatical Relations: The Cognitive Organization of Information. Chicago: The University of Chicago Press, 1991.

DIK, S. C. The theory of functional grammar. Part 1. Dordrecht: Foris Publications, 1989.

HALLIDAY, M. A. K. An Introduction to Functional Grammar. London: Edward, Arnold Publishers, 1985

HENGEVELD, K.; MACKENZIE, J. L. Functional Discourse Grammar: A typologically-based theory of language structure. Oxford: Oxford University Press, 2008.

HIRATA-VALE, F. B. M. A expressāo da condicionalidade no português escrito do Brasil: contínuo semântico-pragmático. Araraquara, 2005, 158 f. Tese de Doutorado (Linguística e Língua Portuguesa), Faculdade de Ciências e Letras, Universidade Estadual Paulista.

HOPPER, P.; TRAUGOTT, E. C. Grammaticalizaton. Cambridge: Cambridge University Press, 1993.

KEIZER, M. E. The lexical-grammatical dichotomy in FDG. Revista Alfa. Advances in Functional Discourse Grammar, v. 51, n. 2, p. 35-56, 2007.

KORTMANN, B. Averbial Subordiators in the Languages of Europe. Towards a Typology and History. Eurotyp Working Papers, v. 8, 1994.

LABOV, W. The boundaries of words and their meanings. In: AARTS, B. et al. FuzzyGrammar. A reader. Oxford: Oxford University Press, 2004. p. 67-90.

LANGACKER, R. W. Foundations of Cognitive Grammar, Vol. 1: Theoretical prerequisites. Stanford: Stanford University Press, 1987.

LAKOFF, G.; JOHNSON, M. Metaphors we live by. Chicago: Chicago University Press, 1980.

LEHMANN, Christian. Towards a typology of clause linkage. In: HAIMAN, J.; THOMPSON, S. (Eds). Clause Combining in Grammar and Discourse. Philadelphia: John Benjamins, 1988. p. 181-225.

LEHMANN, C. Thoughts on Grammaticalization. München: Lincom Europa, 1995.

LONGHIN-TOMAZI, S. R. A perífrase conjuncional "só que": invariância e variantes, Alfa, v. 47, n. 2, p. 139-152, 2003. 
MATHIESSEN, C.; THOMPSON, S. A. The structure of discourse and subordination. In: HAIMAN, J.; THOMPSON, S. A. (Eds.) Clause Combining in Grammar and Discourse. Amsterdam: John Benjamins, p. 275-329, 1988.

NEVES, M. H. M. Gramática de usos do português. São Paulo: Editora Unesp, 2000.

NEVES, M. H. M. 2012. A Gramática passada a limpo: conceitos, análises e parâmetros. São Paulo: Mercado de Letras, 2012.

OLIVEIRA, T. P. Conjunçôes e orações condicionais no português do Brasil. Araraquara, 2008, 155 f. Tese de Doutorado (Linguística e Língua Portuguesa), Faculdade de Ciências e Letras, Universidade Estadual Paulista Júlio de Mesquita Filho.

PAIVA, M. C. Gramaticalização de conectores no portugués do Brasil, Scripta, v. 5, n. 9, p. 35-46, 2001.

PEZZATI, E. G. et al. O estatuto lexical/gramatical das preposições no português. Lusorama, v. 81-82, p. 102-134, 2010.

TAYLOR, J. R. Grammatical Categories. AARTS, B. et al. FuzzyGrammar. A reader. Oxford: Oxford University Press, 2004. p. 293-308.

THOMPSON, S.; LONGACRE, R. Adverbial Clauses. In: SHOPEN, T. Language Typology and Syntactic Description. Vol II: Complex Constructions. Cambridge: Cambridge University Press, 1985. p. 171-234. 